\title{
Rise and Use of New Media and its Relationship to Changing Values of Indian Youth
}

\author{
Dr. Narasimahamurthy N \\ Associate Professor,Dept. of Electronic Media, PK Block, Bangalore University, Palace Road \\ Bangalore-560009 India.
}

\begin{abstract}
The present research is an attempt to examine the relationship between rise and use of new media and change the values, beliefs and attitudes of youths in urban India. Like every major technological change, the new media convergence is having profound effects on virtually all aspects of our society. The 20th century witnessed the convergence of new forms of communication than any other period in history in the field of mass communication. Electricity, the telephone, the automobile, and airplane made the world more accessible to people and transforming our society in the process. As a successive new form of communication has come into being, then the accessible worldwide system of interconnected network called the Internet is publically accessible worldwide, even in India too. Ordinary people have enjoying an expanded quality, range, and choice of entertainment and information content through new communication forms. This new forms of communication has more opportunities than the classical mass media. It is also evident the transformation in lifestyle and value-belief system. While the new media is free and more accessible than classical media or any other forms of medium in history, users can sue it to avoid anything with which they may disagree. New media is emerged as a mainstream medium for information exchange and social interaction across the globe. These media are also a means of forming new cultural contents and means of establishing manners and approaches of how these contents accepted, which has quite an impact on contemporary life styles. The present research tried to understand the correlation between the rise and use of new media and thus altering attitudes values and beliefs of youths, through the use of survey research. For data collection survey questionnaire will be administered to gather appropriate information from different age groups of youths residing in Bangalore City. Relationship between rise and use of new media and changing values, attitudes and beliefs were explored in the course of the study.
\end{abstract}

Keywords: New media, Life styles, Youth, Values, Attitudes, and Beliefs,

\section{Introduction}

India has the largest youth population in the world, around 66 percent of the total population; nearly 808 million is below the age of 35 years. Almost 40 percent of the Indian population is aged of 15 to 25 . The median age in India is just 25.2 years, compared to 34 years in China. Many scholars and development experts argue that by 2020 , India will be the youngest country in the world, with a median age of 29 years, compared with a median age of 37 years in China at that point. The Indian labour force is set to grow by over more than 8 million per annum over the coming decade, most of which will be driven by youth entering the labour market. This pool of youth population needs to be engaged in the mainstream development of the country. India's youth came of age in the late 1990s and early 2000s during a period of relatively high economic growth, which put a television in the majority of Indian homes and made cellphones ubiquitous. Young Indians have grown up more connected to the world-beyond their village, their caste, their co-religionists or their income level compares than any previous generation. Despite several pressing problems such as significant overpopulation, environmental degradation, extensive poverty, and widespread corruption, economic growth following the launch of economic reforms in 1991 and a massive youth population are driving India's emergence as a regional and global power.

The impact of new media on youths is immense and not only changes the way they communicate and interact with other individuals, but also has an overall effect on society and values of youths in general. There is no doubt that new media is one of the most important development $\mathrm{s}$ of modern world which will have a lasting effect on the lives of every human being and largely the youths. Social network sites, online games, videosharing sites, and gadgets such as iPods and mobile phones are now fixtures of youth culture. They have so permeated young lives that it is hard to believe that less than a decade ago these technologies barely existed. Today's youth may be coming of the age and struggling for autonomy and identity as did their predecessors, but they are doing so amid new worlds for communication, friendship, play, and self-expression. New media space enables youth to connect with peers in new ways. Most of the youths use new media to extend the friendship that they navigate in the familiar contexts of school, religious organizations, and sports, cultural, social, and local activities. They can be always on I constant contact with their friends via texting, instant messaging, 
mobile phones and Internet connections. A number of youth also use the online world to explore interests and find information that goes beyond what they have access to at school or in their local community. New media allow for a degree of freedom and autonomy for youth that is less apparent in a classroom setting.

The $20^{\text {th }}$ century witnessed the convergence of new forms of communication than any other period in history in the field of mass communication. Electricity, the telephone, the automobile, and airplane made the world more accessible to people and transforming our society in the process. As a successive new form of communication have come into being, then the accessible worldwide system of interconnected network called the Internet is publically accessible worldwide, ordinary people have enjoying an expanded quality, range, and choice of entertainment and information content through new communication forms. This new forms communication has more opportunities than the classical mass media. Much of those derives from the new media are a very open and accessible medium. The new medium lays open an incalculable choice of information. If people prefer a particular bias, it is readily available in abundance on the new media. While the new media is free and more accessible than classical media or any other forms of medium in history, users can sue it to avoid anything with which they may disagree. New media is emerged as a mainstream medium for information exchange and social interaction across the globe. Many individuals and youths have turned it daily to conduct very diverse information-seeking and communication activities.

A great number of users are information and entertainment consumers and many an additional to become information providers. Most of the new media users contribute content on a wide range of topics in blogs, wikis, and more recently podcasts and videos (Baller and Green 2005, Goodnoe 2006, and Totty 2007). At present the majority of new media consumers use for social interaction. Nearly more than three billion people use new media, which is $40 \%$ of the world population. Most of the new media users go online to keep in touch with friends, relatives, coworkers, and people they know in the physical world. It is establish a new online relationships with people they have never met in person but with whom thy share a common interest. Now user's paly games online with each other, chat and exchange information in chat rooms, discussion, forums, and meeting rooms, visit social and professional networking sites, and visit dating and other social networking sites to meet people for exchange information and acquire new culture. New media is the technical apparatus for communicating with millions of people across the world. The new media is emerging as a so prominent in building a modern state, and their influence extends far beyond local, national boundaries, therefore, it is every much concern about the impact of new media on human attitudes and behavior (Watson, 1998).

\section{New Media in India}

New media is playing an important role in the lives of young people. From mobile phones to social media from video games to virtual worlds, youths are immersed in a technologically rich environment, in a participatory culture where they are not only consuming content but also they producing it and sharing it with others. New media in India have become increasingly popular components of our younger generation's lives in today's modern society. It provides for new generation to communicate, exchange message, share knowledge, and interact with each other regardless of their distance that separates them. The new media links people across the nation regardless of differences and geographical boundaries. The compression of time and space, the convergence of media and the effects of globalization have made the nation into a more interactive. Youths are feeling more comfortable in use and access of new media for communicating and building relationships through online. The middle age group and adults are very comfortable in use of this technology because they are growing with technological era. The youths may not recall how or when they learned to use a computer or access the Internet; for as long as they can remember, those tools were always there. Young people particularly are quick to use the new technology in ways which increasingly blur the boundaries' between their online and offline activities. Contemporary media are also developed rapidly as technology changes with new communication technological dimensions and features. The youths with in the country, who are growing along with new communication technologies, are emerging as "new generation."

Asia is the largest growing continent when it to be increased in the use and access of new media users across the world. Compare to other worlds the new media users growing rate is $15 \%$ annually in Asian continent. This is clearly shows that Asian nations role in the growth of the users of new medium. The two major countries, namely China and India are important contributors to this growth with over more than 500 million subscribers. New media use also on the rise globally, and this change is also evident is increased in India, several studies and reports found evidence that more adults use new media, social media and social networks in India than in any other Asian countries. New media uses in India have become more familiar with the web, its role in providing information has expanded and changed. New media is becoming more and more for youth's attention, not only for searching for information and communications with friends and family but also for the purposes of entertainment. This change is taking eyes away from other traditional media. India is at the race with China in use of new media. India has added around 30\% of the people use new media for different purposes in their day-today lives from past two years, and it is growing at the rate of adding 12.5 million Indian 
users on year to year. Besides the heavy population India stands last when it comes to the average time spent online per visitors, being 12.5 hours. The usage rates are expected to increase as the Internet penetration increases.

New media audience in India is very young compared to the rest of the other nations in the world. Nearly $75 \%$ of new media users in India are under the age of below 35 years and nearly half of them are under 25 years of age. These usage patterns show that the expansion, adaptability and future prospects of the new media in India. Searching information, social networking, e-mail are the top most for the users to use new media in their day-today activities in India. Nearly more than $84 \%$ online audience will use social networks for different purpose of communication and other online activities. It is clearly shows that the young generation is leading the new media revolution in India. The growth and use of new media by younger generation in India for the purpose of their Information and entertainment is leading and going by the current trends.

\section{India youths in Digital Age}

The country has undergone tremendous alteration in its outlook, behaviors, beliefs, culture and practices in the last two decades or so. The change is coincides with the post liberalization and new media convergence in India. Understandably this issue has been one of the popular areas of research among scholars and academicians. This part of the review deals with certain widely known and established values, beliefs and common practices and their alteration in the last two decades. The use of digital media in India is set to grow rapidly. India currently more than 400 million Internet users making it the third-largest user base in the world; the number of users is set to increase on year to year, and this will make India the second largest national group behind only China. The young and dynamic user population driving the growth of online consumption and using these digital media in sophisticated ways that are in line with developed countries. Indian Internet using will have uniquely Indian flavor, making local content development and innovation particularly important. India youths are adopting the Internet at a much rapid than advanced economies.

The rapid spread globally of digital media has been credited with many world-wide social, political, cultural and economic changes. The scholarly tendency has been to treat young people born in and after 1990 as the digital generation with an orientation toward digital content and lifestyles (Katz, 1996) and that is one of the reasons for the surging interest in youth digital cultures. The spread of new media technologies have had an accelerating impact on each other. Young people today grow up at the intersections of these two large forces. Individuals in different geo-political and socio-economic locations, however experience the intersections in vastly different ways. It is important to note the immense diversity in the Indian youth population. India is a country with deep and huge structural divides. These divides heavily influence the life experience of young people of the country. Class, caste, gender, geographical location, parental education and values, schools and infrastructure, and language proficiency are only some of the factors that interest in shaping a young person's engagement with digital media.

In India nearly $67 \%$ of young population lives in the rural areas with least influence of globalization, high traditional values. They are least economically privileged, most family oriented Bollywood influenced generation. Another section of the country nearly it constitute that $31.5 \%$ young generation have moderate global influence. They are well aware of the global trends but rooted to the Indian family values, customs and ethos. The last section of the Indian society are basically the creamy layers and marginal $1.5 \%$ youth population of the country and it is marginal in number they are strongly growing and well affluent and consume most of the trendy and luxury items. They are very high Internet savvy and believers of the global-village concept, highly influenced by the western music, food, fashion and culture but yet they are Indian at heart (Sengupta, 2012). All these division when oversimplified, show how India's youth have quite different lives. The present study is to understand rise and use of new media and its effects in changing values of Indian youth with explaining the nature of youths in digital age in India.

The present research is to discuss the understand the rise and use of new media influence the way the Indian youths will perceive their own culture, values, beliefs and, in many cases results in an enhanced preference of the 'other' privileged culture and value system. The country has been in the midst of rising debates in respect of influence of new media on the society and youths. Several attempts have been made in the past go explain the changing values and the emerging neo-culture in Indian youth, however most of these studies have been ideological rather than based on social scientific perspectives. The present study is to try to systematically measure the relationship between rise and use of new media and changing values of Indian youths. To test these relationships between new media and changing values, the following specific research question were proposed for the study.

RQ1: In what extent new media change the values of youths

RQ2: What is the relationship between new media and values?

RQ3: What values are most important to youth population in urban India? 


\section{Research Methodology}

The aim of this research is to examine the rise and use of new media and its relationship to changing values of urban youths in India. Therefore I gathered the information and collected the representative sample of urban youth's population. The present research is based on recent surveys of rise and use of new media among urban youths in Bangalore city. The broad area of survey research encompasses any measurement procedures that involve asking questions of the respondents. A 'survey' can be anything forms a short paper and pencil feedback from to an intensive one-on-one in-depth interview. In this present study I sued the questionnaire schedules for data collection. Questionnaires are an inexpensive way to gather data from potentially large number of respondents. A well-designed questionnaire that is used effectively can gather information on both the use and access of new media and its relationship to change the values and attitudes of the youths. The target population for this study is youths in Bangalore city and those who are getting access and use of new media in their daily lives. The relationship between media use and access and the values considered important by the respondents is examined. Further the present research discuss some interesting results of that new media diffuse at a rapid rate amongst the youth and play an imperative role in their lives which is sometimes beyond comprehension for significant of others.

Different genders have given their opinion, there are $238(61.49 \%)$ respondents are belonging to male and $149(38.50 \%)$ respondents are female. There are different age groups of respondents also have given opinion for the present research, there are 138 (35.65\%) respondents are in the age group of 18-20, nearly same percent of respondents are belong to $21-23$ age group in this study nearly $72 \%$ of respondents have belong to the age group of $18-23$, it is the age group of digital natives group. There are $21 \%$ of the respondents have belong to the age group of 24-26 and only 3.10\% respondents have belong the age group 27-29. A small percent of respondents have come from in the group of 29-33 and above, because their usage of new media is less compare the age group of 18-23. In respect of educational level of the respondents, there are $26.63 \%$ of respondents are belong to secondary education, $25.83 \%$ of respondents have belong to the graduate, $26.09 \%$ of respondents have post-graduate and $21.44 \%$ of respondents are professional educational background.

\section{Findings and analysis}

To establish relationship between rise and use of new media and change the values, beliefs and attitudes of youths in urban India and changing values, people between the age groups of 18-33 and above were requested complete the answers for the survey questions. This particular set of respondents was chosen because this age group is considered 'most impacted' by the changing nature use of new media, and this age group is considered as digital natives. Accurately measuring new media use and rise of new media in its relationship to changing values and beliefs has been, and continues to be a difficult challenge. In the present study survey research is employ to measure the relationship between use of new media and changing values of youths and the kind of content to which they exposed. In the digital age, measurement questions are complicated by such seemingly simple questions as ownership, use of new media, extent of use and rise of new media etc., were measured in this study. As new media communications and the Internet become increasingly pervasive, Urban Indians continue to highly access to these new media revolutions. Urban are among the citizens to gain access to the Internet with use of new media becomes an important aspect.

The present research is based on the field data. A structured questionnaire was prepared and survey has been conducted to collect the data. After collecting the data it has been analyzed with the help of tables to present them an understandable form. New media are part of the lives of many young people today. New media may be 'new' in the eyes of many researchers, but to the younger generation who literally grew up with digital technologies they are nothing extraordinary and new forms of communication and information retrieval. Youth is often seen as a distinct generational cohort subject to common process of socialization and identity formation. The notion of 'youth culture' also implies a different set of cultural expressions and life experience.

Table 1.1 owning of mobile and Internet facilities

\begin{tabular}{|l|l|c|c|}
\hline \multirow{2}{*}{ Do you have mobile phone? } & & Frequency & Percent \\
\cline { 2 - 4 } & Yes & 368 & 95.09 \\
\cline { 2 - 4 } & No & 19 & 4.90 \\
\cline { 2 - 4 } & Total & 387 & 100 \\
\hline \multirow{2}{*}{ Do You have Internet facilities in your Mobile? } & Yes & 219 & 56.58 \\
\cline { 2 - 4 } & No & 168 & 43.41 \\
\cline { 2 - 4 } & Total & 387 & 100 \\
\hline
\end{tabular}

The table no 1.1 reveals that owning the mobile phone of youths of both male and female from total population of 387 on which questionnaires were distributed and survey was carried out. There are $368(95.09 \%)$ of respondents of both male and female were said they have mobile phone and only 19 (4.90\%) of respondents have said they do not have mobile with them. The above table shows that mobile phone is very popular among 
youths because $95 \%$ of youths own mobile phone. In respect of Internet facilities in their mobile phone nearly $219(56.58 \%)$ of youths said they have Internet facilities in their mobile and $168(43.41 \%)$ said they do not have Internet facilities in their mobile phone. The above table shows that majority of the youths will have Internet facilities in their mobile phone and Internet is very useful and very essential to youths.

Table 1.2 Internet facilities and Internet use

\begin{tabular}{|l|l|c|c|}
\hline \multirow{4}{*}{ Do you have Internet connection in your home? } & & Frequency & Percent \\
\cline { 2 - 4 } & Yes & \multicolumn{1}{|c|}{10} & 2.58 \\
\cline { 2 - 4 } & No & 377 & 97.41 \\
\cline { 2 - 4 } & Total & 387 & 100 \\
\hline \multirow{5}{*}{ Do you use Internet } & Always & 90 & 23.25 \\
\cline { 2 - 4 } & Very often & 74 & 19.12 \\
\cline { 2 - 4 } & Some times & 77 & 19.89 \\
\cline { 2 - 4 } & \multirow{2}{*}{ Occasionally } & 92 & 23.77 \\
\cline { 2 - 4 } & Never & 54 & 13.95 \\
\cline { 2 - 4 } & Total & 387 & 100 \\
\hline
\end{tabular}

The table 1.2 reveals that the having Internet facilities in their home and use of Internet by all the respondents, there are only $10(2.58 \%)$ of respondents have said they have Internet connection in their home and $377(97.41 \%)$ of respondents said they do not have Internet facilities in their home. It indicates having Internet facilities in their home are very low the access of Internet connection to home is very low means it shows that affordability and awareness are very important factor. Another question is the use of Internet among respondents all the respondents have opined that in different ways, there are $23.25 \%$ respondents said they use Internet always and 19.12\% respondents said they use Internet very often, 19.89\% respondents said they use Internet in some times and $23.77 \%$ respondents use Internet in occasionally and $13.95 \%$ respondents are never use Internet. This is indicates that majority of the respondents use Internet in different manner and still there is small section of the society is never use Internet.

Table 1.3 Usage of Internet among youths

\begin{tabular}{|l|c|c|}
\hline & Frequency & Percent \\
\hline Less than one hour & 255 & 65.89 \\
\hline More than one hour & 37 & 9.56 \\
\hline More than two hours & 26 & 6.71 \\
\hline More than three hours & 15 & 3.87 \\
\hline Never & 54 & 13.95 \\
\hline Total & 387 & 100 \\
\hline
\end{tabular}

Table 1.3 shows that the Internet usage among youths on how long they use Internet for their information and entertainment. There are $65 \%$ respondents have said they use Internet less than one hour in a day may be in mobile which they use to browse Internet they could not use more time therefore majority of them have said they use Internet less than an hour. There are $9.56 \%$ of respondents said they use Internet more than one hour may they use cybercafé or they might use college library, office and other place. There are $6.71 \%$ of respondents have said they use Internet more than two hours in a day. It indicates most of the professional educational degree youths are use Internet more than two hours in day for their educational purposes. The study found that there are still 13.95\% of youths are not at all using Internet it seems the access and lack of computer literacy and their interest to use Internet are all concerned. Further it find that there is clear digital divide with in the society.

Table 1.4: New media usage for different purposes by youths -Always?

\begin{tabular}{|l|c|c|}
\hline & Frequency & Percent \\
\hline To get information & 39 & 10.07 \\
\hline For entertainment & 9 & 2.32 \\
\hline To chat with friends & 52 & 13.43 \\
\hline For e-mail & 44 & 11.36 \\
\hline Play games & 36 & 9.30 \\
\hline To connect with others & 42 & 10.85 \\
\hline To pass leisure time & 26 & 6.71 \\
\hline Educational purpose & 35 & 9.04 \\
\hline To learn culture & 32 & 8.26 \\
\hline For some other purpose & 18 & 4.65 \\
\hline Never use & 54 & 13.9 \\
\hline Total & 387 & 100 \\
\hline
\end{tabular}


Table 1.4 represents the new media uses for different purposes among youths in urban centers. There are $10.7 \%$ of the respondents use Internet and new media for getting information, $2.32 \%$ of respondents have use new media for entertainment purpose, $13.43 \%$ of respondents have said they use Internet facilities to chat with friends, $11.36 \%$ of respondents opined they use Internet for e-mail correspondence purpose, there are $9.30 \%$ of respondents use new media for to play games, $10.85 \%$ of respondents have said they use new media and Internet for to connect with others, there are $6.71 \%$ respondents use new media for to pass leisure time, $9.04 \%$ of respondents have said they use Internet for the purposes of educational information, $8.26 \%$ of respondents have said they use Internet for to learn culture, there are $4.65 \%$ of respondents have said they use Internet for some other purpose means to browse to pornography, to see adult sites etc., and there are $13.9 \%$ of respondents have said they never use Internet at all it seems there are some percent of population is still exist non users of Internet and new media because of not interested and lack of computer literacy. The present study is found that new media is very effective and bringing changes among youths. Majority of them use Internet for Information, to chat with others, educational purpose to connect with other and e-mail correspondence. It shows that the strong relationship between new media and youths, and it clearly indicate new media consumption is rises in day-by-day.

\section{Respondent's perception of New Media in relation to changing values}

More and more young people in developing societies today are placing themselves at the vanguard in terms of the adoption of new information communication technologies and depending on new media, of these new media technologies affect the lives of youths in relation with changing the values. New media are increasingly becoming a common feature in the different arenas of everyday life in Indian societies, at home, school, workplace, community, and politics and among other areas. The young generation of the nation enjoys and access to and often adopt new media faster than in other countries. Our upcoming generation is very much part of the 'net-generation' which were born, and growing up with new media. This change is in relation with cultural values in rapid change. The present research is to found that the strong relationship between new media changing values.

Table 1.5 New media effects on youths

\begin{tabular}{|l|l|c|c|}
\hline \multirow{5}{*}{ New media change the values of youths-Do you agree? } & & Frequency & Percent \\
\cline { 2 - 4 } & Strongly agree & 106 & 27.39 \\
\cline { 2 - 4 } & Agree & 130 & 33.59 \\
\cline { 2 - 4 } & Strongly disagree & 39 & 10.07 \\
\cline { 2 - 4 } & Disagree & 24 & 6.20 \\
\cline { 2 - 4 } & I don't know & 88 & 22.73 \\
\cline { 2 - 4 } & Total & 387 & 100 \\
\hline \multirow{5}{*}{ New media change the attitudes of urban youths-Do you agree? } & Strongly agree & 99 & 25.58 \\
\cline { 2 - 4 } & Agree & 119 & 30.74 \\
\cline { 2 - 4 } & Strongly disagree & 49 & 12.66 \\
\cline { 2 - 4 } & Disagree & 31 & 8.01 \\
\cline { 2 - 4 } & I don't know & 387 & 22.99 \\
\cline { 2 - 4 } & Total & 387 & 100 \\
\hline
\end{tabular}

Table 1.5 reveals that new media effect on youths. The above table shows that for new media change the values of youths, there are $27.39 \%$ of respondents have said they strongly agree, $33.59 \%$ of respondents said they agree the statement, there are $10.07 \%$ of respondents have strongly disagree, $6.20 \%$ respondents have said they disagree of this stamen and $22.73 \%$ respondents said they don't know. The study indicates that majority of respondents have agreed that new media change the values of youths it means new media brings the changes in youths vales. The study found that new media clearly bring the changes in their values.

For another statement of new media changing the attitudes of urban youths, there are $25.58 \%$ of respondents have strongly agreed, there are $30.74 \%$ of respondents have agreed new media bring the changes in youths attitude of urban youths, there are $12.66 \%$ of youths have strongly disagreed the stamen of new media bring the changes attitudes of urban youths, and $8.01 \%$ of respondents have disagree and $22.89 \%$ of respondents said they don't know about this changes. The study found that there is strong relationship between new media and youth's attitude change. Majority of respondent have agreed new media brings the changes in attitudes of urban youths. The above table 1.5 clearly shows that new media influence on youths attitudes. 
Table 1.6 New media effect on youth's culture

\begin{tabular}{|c|c|c|c|}
\hline \multirow{7}{*}{$\begin{array}{l}\text { New media change the culture of urban youths-Do you } \\
\text { agree? }\end{array}$} & & Frequency & Percent \\
\hline & Strongly agree & 117 & 30.23 \\
\hline & Agree & 102 & 26.35 \\
\hline & Strongly disagree & 47 & 12.14 \\
\hline & Disagree & 35 & 9.04 \\
\hline & I don't know & 86 & 22.22 \\
\hline & Total & 387 & 100 \\
\hline \multirow{6}{*}{$\begin{array}{l}\text { New media is the entertainment medium for urban } \\
\text { youths- Do you agree? }\end{array}$} & Strongly agree & 110 & 28.42 \\
\hline & Agree & 106 & 27.39 \\
\hline & Strongly disagree & 60 & 15.50 \\
\hline & Disagree & 29 & 7.49 \\
\hline & I don't know & 82 & 21.18 \\
\hline & Total & 387 & 100 \\
\hline
\end{tabular}

Table 1.6 reveals that the statement of new media changing urban youth culture, were asked the questions there are $30.23 \%$ of respondents have strongly agreed, there are $26.35 \%$ of respondents have agreed new media is changing the culture of urban youths. There are $12.14 \%$ respondents did not agreed means strongly disagree, $9.04 \%$ respondents have disagreed new media may not change the urban youths culture, and $22.22 \%$ respondents have said they don't know how new media change the culture of urban youths. The present study found that the new media have become the place where young people most find their opportunity to explore and express their identities and their social relations, and navigate their way through the values that are on offer around them. The above tables clearly shows that digital generation is overthrowing culture and knowledge as we know it and that its members are engaging in new media in ways radically different from those of older generations. At the same time we also believe that this generation is at a unique historical moment tied to longer-term and systemic changes in sociability and culture.

The statement of new media is he entertainment medium for urban youths, there are $28.42 \%$ of respondents have strongly agreed, $27.39 \%$ of respondents have agreed the statement and $15.50 \%$ of respondents have strongly disagreed, $7.49 \%$ respondents have disagreed the statement of new media is the entertainment medium for youths. There are $21.18 \%$ of respondents have said they don't know the above statement. The study finds that there is strong relationship between new media and entertainment. The above table reveals that majority of the urban youths are depend new media for their entertainment. Urban youths are live in digital age that gives them easy access to wide variety of new media content, video games, movies, music forms are the content of entertainment. New media provide entertainment for urban youths it can increase their ability to learn, communicate and become force for good in the urban centers.

\section{Conclusion}

A key to understand new media transformation of new culture and values on urban youths in Bangalore city it depend new media and its implication. New media dependency was predicted by the subjective information utility of the Internet as source of comprehensive local, national and international information. Urban youths were unsurprisingly, more likely to be high dependent on the new media and spend more time. New culture was positively associated with dependency and use of new forms of communications. Globalization and opening up of the Indian economy have introduced Indian society to new cultural and social norms. However, this process has not eradicating traditional Indian values and beliefs. But the new generation of the country in particular youths wants the best of both worlds. Social networks such as Facebook, Twitter and other sites are driving new forms of social interaction, dialogue, exchange and collaboration. These new media enable users to swap ideas, to post updates and comments, or to participate in activities and events, while sharing their wider interest. New media dependency serves the users into fast-flowing online conversation, helping individuals, friends and colleagues to contribute to debates or learn many thing even a new culture from others. Since the Internet breakthrough as a new mass medium, it has become a topic of wider discussion of implication for society. Many of them find new media has great benefits and consider the Internet a tool for freedom, commerce, connectivity and other social benefits especially the culture. Social and cultural assessments of the new media dependency are very useful because it can guide policies for the design, regulation and dependency of new media. The study finds that there is a strong relationship between new media and youths values and culture. 


\section{References}

[1]. Baller and Green 2005, Goodnoe, 2006, and Totty 2007 Blogs will change your business. Bus. Week. 3931 Aug., 10. 56. Wiki while you work. Inform. Week 1078, 3.. Technology: How to be a star in a YouTube world. Wall Street Journal Online. May 14.

[2]. Blamchand, A L, 2004-The effects of Dispersed Virtual Communities on Face-to-Face Social Capital, In Social Capital \& Information Technologies, MIT Press Cambridge M A, 53-74.

[3]. Chindamabram\&Bostrom 1997 Group Development (II): Implications for GSS Research and Practice" Group Decision and Negotiation, 6(3), pp. 231-254

[4]. Clifford Geertz, 1973- The Interpretation of Culture (Basic Books, New York)

[5]. Ember and Ember 1990-Cultural anthropology (6th ed.). New Jersey: Prentice Hall.

[6]. Hagel J \& Armstrong, A G 1997- Net gain: expanding markets through virtual communities. Boston: Harvard Business School Press.

[7]. Hiltz R 1993-The Virtual Class room-Learning without limits via Computers Networks. Norwood, N J Ablex Publishing

[8]. Howard Rheingold 1994- A Slice of life in virtual community In L M Horasim (ed) Global NetWorks

[9]. Katz, J. E., \& Rice, R. E. 2002- Social Consequences of Internet Use: Access, Involvement and Interaction. Cambridge, MA: MIT Press.

[10]. Nanda, S 1991Cultural anthropology (4th ed.). Belmont, CA: Wadsworth.

[11]. Park \& Floyd, 1996-Making Friends in Cyberspace, Journal of Computer Mediated Communication 1(4)

[12]. Preece, 2000- Online communities: Designing usability, supporting sociability. Chichester, England: John Wiley \& Sons.

[13]. Preece, J. and Maloney-Krichmar, D. 2002- Online communities: Focusing on sociability and usability. In J. Jacko\& A. Sears (Eds.), The Human-Computer Interaction Handbook (pp. 596-620). Mahwah, NJ: Lawrence Earlbaum Associates.

[14]. Roberts T L, 1998-Are Newsgroups, Virtual Communities; talking on the net, Conference paper -human factors on Computing System.

[15]. Ridings and Gefen 2004- Virtual Community Attractions: Why people hang out online, Journal of Computer Mediated Communication Vol. 10 Issue 1

[16]. Wellman, 1999- The Networked nature of community: Online and offline. IT \& Society, 1 (1), 151-165. 